Dorota Gaskins*, Maria Frick, Elina Palola

and Antje Endesfelder Quick

\title{
Towards a usage-based model of early code- switching: Evidence from three language pairs
}

https://doi.org/10.1515/applirev-2019-0030

Abstract: Usage-based studies trace children's early language back to slot-andframe patterns which dominate spontaneous language use. We apply the Traceback method to data from three bilingual children with English as one of their languages and Polish, German, or Finnish as the other to examine what these children's code-switching has in common and how it differs in light of the genealogical distance between the languages used. Their bilingual constructions are derived from individual corpora of naturalistic interactions of each child respectively and traced back to monolingual language produced previously to establish whether they are unprocessed chunks or partially schematic units. Based on this, we propose a model of switching which helps us to distinguish between the qualitative aspects of bilingual use in these two types of combinations. Our results show that all three children filter out some mixing occurring in chunks before these give basis to longer units. Whatever bilingual combinations remain frozen in those units can be explained by phonological overlap of the children's two languages, which is highest in the acquisition of English-German due to their genealogical proximity.

Keywords: slotandframe, codeswitching, childhood bilingualism

\section{Introduction}

The term code-switching (CS) captures a broad range of cases which combine lexical and grammatical features of the speaker's two languages within a single

*Corresponding author: Dorota Gaskins, Applied Linguistics and Communication, Birkbeck College School of Languages Linguistics and Culture, London, United Kingdom of Great Britain and Northern Ireland, E-mail: dorota.gaskins@candi.ac.uk

Maria Frick, Department of Languages and Literature, University of Oulu, Oulu, Finland Elina Palola, University of Oulu, Oulu, Finland

Antje Endesfelder Quick, Institute of British Studies, University of Leipzig Faculty of Social Sciences and Philosophy, Leipzig, Germany 
conversational turn. Models of bilingual production account for CS by calling upon the cognitive architecture of the bilingual mind which has the capacity for the language representations to be interconnected and therefore co-activated in the moment of speech (e.g. Bartolotti and Marian 2013). Currently much more is known about adult CS than children's CS. However, emerging evidence suggests that child CS is also facilitated in areas of structural convergence (e.g. Quick Endesfelder et al. 2016) and phonological overlap (Namba 2012). In fact, children with specific language impairment switch less and are unable to integrate their two languages in a sophisticated manner which is a reflection of their difficulties in discerning areas where the structures of their two languages overlap (Pert 2007). Child CS across language communities appears to display common patterns of use where one language tends to provide a structural framework for the other to be embedded into (Gawlitzek-Maiwald and Tracy 1996; ; Bernardini and Schlyter 2004). There is, however, a high degree of variation in how children combine their two languages which can be best explained by language usage. Child CS is prone to change as a result of increased exposure to the weaker language (Pfaff 2011; Quick Endesfelder etal. 2018) and of frequencies with which individuals use own words and phrases which determine the intra-sentential switching points (Gaskins et al. 2019). Usage-based (UB) research in adult CS has enjoyed increased attention (see studies in this volume); however, that in child CS is only beginning to emerge. Thus our study, rooted in UB theory, aims to contribute to our understanding how simple usage requirements determine the way all three children studied here combine their two languages. We also link properties of the child's two languages with the way different language pairs are combined. With these aims in mind, we compare bilingual CS in children exposed to three language pairs to the children's prior output.

\subsection{Structural approaches to code-switching}

Although we use the term code-switching, our understanding of the concept differs from that used elsewhere in the literature. CS research carried out in the past few decades has focused mostly on constraints which apply to child CS across language pairs. It was conducted in light of the idea that one of the speaker's two languages provides a matrix language frame (MLF) into which 'constituents' (either single lexical items or whole phrases) from the other language are inserted, thus assuming an imbalance of the two languages (Myers-Scotton 1993 [1997]; Myers-Scotton and Jake 2001). This idea of bilingual asymmetry resonates in the models of Gawlitzek-Maiwald and Tracy (1996) and Bernardini and Schlyter (2004) who show how mixing proceeds when one 
language is dominant and provides a functional skeleton for the weaker language to grow into. However, these child CS accounts rely heavily on several assumptions. The first one is that there is a strict distinction between syntax, which is present in some form from the onset of speech, and lexis, which is acquired from input. Meanwhile, there is substantial evidence that lexicon and grammar are tightly interwoven, with the former emerging from the latter through intermediate low-scope schemas such as frozen chunks and partially schematic units (PS) (e.g. Stoll et al. 2009; Lieven et al. 1997; Keren-Portnoy 2006). The second assumption is that in each bilingual utterance, there is a division of labour between two speaker's two languages and that only one language provides a functional frame while the other elements embedded into it. As a result, mixing is understood to be a unidirectional phenomenon to be examined in separate sociolinguistic contexts. However, more current research reveals that children mix bi-directionally, with functional items derived from either language, depending precisely on contexts of use (e.g. Müller et al. 2015). The third assumption is that bilingual mixing is constrained by universal mechanisms and therefore manifested in similar ways across language pairs. Yet while similar trends have been indeed documented across pairs (e.g. Lanza 1997; Deuchar and Quay 2000; Cantone 2007), children are often reported to violate the proposed universal constraints, showing, for example, that it is not nouns but predicates, such as verbs, adjectives and some closed-class items which have the highest numbers of mixed tokens (e.g. Deuchar and Vihman 2005) and that functional items are sometimes mixed from the weaker to the stronger language (Müller et al. 2015). Therefore, our study will depart from the MLF approach in favour of one which is informed by language usage.

\subsection{Towards a usage-based model of code-switching}

Our study is rooted in UB theory which has variation at its core. UB theory belongs to a group of approaches which see language acquisition as reliant on cognitive processes which are central to all types of learning, and therefore as deeply grounded in the child's experience with her input and own output (Bybee 2001; Tomasello 2003). At the heart of these models lies the concept of language constructions, form-meaning parings, which emerge with mounting exposure to language. One engine for construction building is through increasing utterance length: when two or more words such as Give me that are joined together in speech, they form a frozen chunk until the child uses one of their component parts in conjunction with a novel word. This marks the point at which the construction is conceptually segmented into a PS unit such as Give me X, for 
example, with Give me used as a frame and $X$ marking a slot which typically hosts items initially very similar, and only later more distant to the word that (Bybee 2001). The main force driving acquisition of frames is their sheer frequency in child-directed speech: links have been found, for example, between highly repetitive and salient utterance-initial elements found in the input of monolingual Russian, German and English two-year-olds, such as Do you want $X$ ?, I've $X$, Did $X$ and the earliest constructions produced by these children which also revolve around a highly restricted number of lexical items and which also tend to be used in utterance-initial positions (Stoll et al. 2009). In children exposed to one language, frame-based schemas such as Put in $X, I$ want to $X$ and Go to $X$ account for the average of $60 \%$ of children's first 400 constructions recorded in a diary and on video between the ages of 1;0 and 3;0 (Lieven et al. 1997). Proportions of such schemas can reach $78 \%-92 \%$ if two-year-old children are video recorded on a dense sampling schedule (Lieven et al. 2009). Frequency of use increases the strength of representation of such schemas as it allows them to become fully processed, conceptualised and entrenched in use (Schmid 2017). In the process, type frequencies lead to increased productivity, typically measured as type to token ratios (TTR): the more word types are produced in the slot of the construction Give me $X$, the sooner the slot becomes receptive to new language via rule-based assembly (Schmid 2017). For the rule-based assembly to be possible in the case of Give me X, the child needs to realise that a) the slot X hosts items which denote objects such as food and drink, for example, and that b) some words such as milk or teddy refer to objects rather than qualities or actions. We believe that in studies of small corpora, such as this one, it is type frequencies rather than token frequencies which can help us to understand the qualitative nature of child language.

Another engine for construction building is automation: when the stretch Give me that emerges in use, its versatile character is likely to encourage repeated processing which automates the transitions between its component parts and facilitates holistic production of the chunk by means of access and retrieval rather than an online computational procedure (Schmid 2017). Using the construction Give me that repeatedly results in high token frequencies of the string and facilitates its holistic recall without the need to assemble it spontaneously in the moment of speech. Importantly, the mere existence of an automated chunk such as Give-me-that does not preclude the presence of a fullyschematic pattern: the non-redundancy of the linguistic constructions means that the same construction may be activated in accordance with a given grammatical rule or via lexical means in the form of a frozen lexical item though the latter appears to be a preferred production route as it is less costly to the speaker (Walsh et al. 2010). It is this view which will allow us to examine the extent to 
which CS can be accounted for by such low-scope schemas as chunks and PS units without the need to rely on the notion of underlying linguistic representations.

Our study follows on from what has already been established through previous UB research in child CS. Quick Endesfelder et al. (2018a) were the first to analyse CS in a corpus of a German-English speaking child aged 1;103;1 and reduce all his audio recorded CS constructions to four categories: 1) unprocessed 'frozen' chunks (e.g. Hilf me 'help me'); 2) PS units with chunks in the open slot (e.g. Let's + kaput machen 'Let's break it'); 3) PS units with single words in the open slot (e.g. Ich want + apple 'I want apple'); 4) 'other' utterances which did not fit in within the other categories (e.g. Ein open Mama 'one open Mama'). They report that $60 \%$ of all CS utterances belong to the category of PS units, with an open slot hosting single items from one of the child's languages and a further $11 \%$ with an open slot hosting chunks from either language (Quick Endesfelder et al. 2018a). Their data thus suggest that high numbers of CS constructions can be explained by openness of slots to material from either language, at least in those examples where the frame is in one language and the slot filler in another. We also know, however, that productivity of constructions is not the ultimate explanation for why such constructions are open to elements from another language: The $X$, for example is one of the most productive constructions found in the corpus of a PolishEnglish bilingual two-year-old but not a single instance of mixing has been recorded within this construction; instead semantic and structural autonomy of key words in the frames seem a more reliable explanation for why The and other similar frames were combined with items from another language (Gaskins et al. 2019).

Seeing that CS is present both in PS units and in frozen chunks (Quick Endesfelder et al. 2018a), we propose a model of early CS which we will test in this study. We believe that if two languages are separate in the input and the child continues to mix, mixing must be developmental (Gaskins et al. 2019). The first step of such use is the first instance of words from either the same language or two different languages being combined spontaneously in online production (see Figure 1). The second step is mere repetition of that same stretch of speech which leads to its automation. The third step is combining the automated chunk with slot fillers from either language. This cycle is perpetual: every PS unit revolves around a chunk which has been automated through repeated use but once that PS unit invites holistic processing, it becomes a chunk in its own right, and subsequently gives rise to new PS units through the addition of new open slots. It is also important to mention that while the second step may be provoked by the need for 


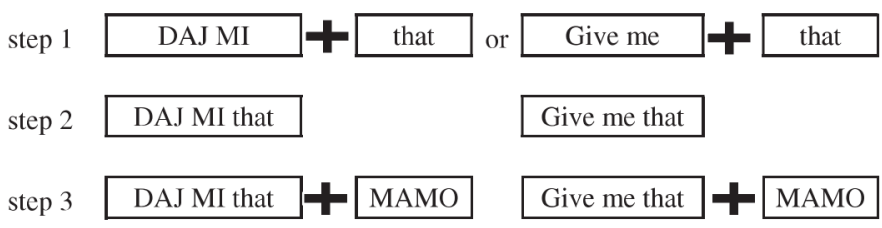

Figure 1: A UB model of early CS: DAJ MI that, MAMO! 'Give me that, mummy'.

cognitive ease (Walsh et al. 2010), the first and the third involve a degree of productivity (Quick Endesfelder et al. 2018a; Gaskins et al. 2019). Quick Endesfelder et al. (2018a) report that $18 \%(\mathrm{n}=239)$ of all CS utterances are chunks, such as those illustrated by step 2 (Figure 1) and of the mixed PS units, such as those in steps 1 and 3 (Figure 1), 56\% $(n=655)$ have mixed frames, identified via at least one previous occurrence of words from two languages in combination with a variable slot.

We are interested, however, in why Tim, the child discussed by Quick Endesfelder etal. (2018a) had high proportions of bilingual frames such as that in Ich want $X$ 'I want X'. It is now widely accepted that attention is crucial for language acquisition, and input does not become intake unless it is noticed and consciously registered (Tomasello 2003; Schmidt 2010). It is expected that attention is also crucial in language production though its exact impact on CS is not yet clear. We would assume that the production of PS units involves increased levels of attention and that this should mean that CS is filtered out of Tim's frozen chunks. This would be expected at least in contexts where the child's two languages are kept separate in the input, as was the case with Tim's input. It is, however, possible that the filtering is less likely in English-German acquisition due to genealogical closeness of the two languages than it would be in other languages. We believe it is important to show what happens between stages 2 and 3 in children who a) are exposed to different language pairs and b) are exposed to bilingual input in separate manners, for example through the one-parent-one-language strategy (OPOL). This is one of the questions we aim to address through our study.

\subsection{Rationale for the study}

So far, UB studies have explored CS in individual children (Quick Endesfelder et al. 2018a; Quick Endesfelder et al. 2018; Gaskins et al. 2019) or several children from the same language group (Quick Endesfelder et al. 2018b). Our study will continue to explore language contact phenomena by extending the 
usage-driven analysis of CS utterances to three language pairs: English-Polish, English-German and English-Finnish. UB theory allows us to apply the slotand-frame model of analysis to children who acquired their two languages either simultaneously from birth or consecutively; this is due to the fact that this acquisition model assumes that bilingual constructions are built from input and this, in turn, means that they could be built at any point a second language is introduced, be it at birth or at any other point in life. Studying agematched children across three language communities will help us to address our main research question: are there any common strategies in all three children's use of low-scope patterns such as chunks and PS schemas? To address this question, we will analyse the distribution of children's lowscope schemas in spontaneous speech and compare the extent of mixing in chunks and PS units. This analysis will help us to understand whether the observations made by Quick Endesfelder et al. (2018a) are restricted only to German-English or whether they also hold for other language pairs and therefore can be explained in light of processing skills used by young bilingual speakers. This study design also holds the promise to shed light onto differences in mixing which could be then linked to the genealogical differences between Polish, German and Finnish.

\section{Participants and data}

\subsection{Participants}

The first participant of this study is Sadie, a first-born, normally developing female child participant. During data sampling, Sadie was a single child; born to a Polish-native mother and an English-native father, she lived in England and heard both languages on a daily basis at home from the day she was born. Her parents adhered to the OPOL strategy when speaking to Sadie but used English to communicate with each other, meaning that Sadie was aware of her mother's ability to understand English. From the age of one, Sadie was exposed to English in nursery three days a week. A diary, kept to document Sadie's input patterns on a daily basis, shows that in the second and third year of life approximately 25\% of her input was in Polish and 75\% in English (see Gaskins et al. 2019). Sadie's preferred language of interaction was English: video recorded interactions show that at the age of 2;3 she had 292 (74\%) English words and 102 (26\%) Polish ones in her productive lexicon; while her MLU in monolingual English utterances $(n=4,191)$ increased from 1.63 at $1 ; 10.16$ to 2.35 at 2;05.11, her MLU in 
monolingual Polish utterances (142) dropped from 1.03 at 1;10.20 to 1.0 at 2;04.15. Sadie was recorded between the ages of 2;00.09 and 2;05.11 for the total of 780 minutes.

The second participant is Sylvie, the only child, and a normally developing daughter of an English-speaking mother and a German-speaking father. Sylvie lived in Germany and heard both languages on a daily basis from the day she was born. Her parents also adhered to the OPOL strategy but interacted in German between each other, meaning that Sylvie also must have been aware of her mother's ability to understand German. From eighteen months onwards, Sylvie attended childcare 45 hours per week where she interacted with carers and peers exclusively in German. This is reflected in her MLU of 2.37 as recorded in her German utterances ( $\mathrm{n}=2,223$ ) compared to the MLU of 1.89 in her English utterances $(n=298)$. At the time of data collection, Sylvie had approximately 75\% of her input in German and 25\% in English. Sylvie was recorded between the ages of 2;4 and 2;5 for the total of 340 minutes.

The third participant is Eetu, a seventh-born, normally developing boy recruited for this study. Eetu was born to Finnish parents and raised in Finland together with his six siblings. Eetu's parents spoke exclusively Finnish at home. English was introduced to him at the age of 2;2 by an English-speaking live-in au-pair who used very occasional switches into Finnish. Between 2;2 and 3;1, Eetu spent six hours a day, five days a week alone with the au-pair and his five-year old brother, who had also been raised monolingually at first. He spent the rest of his waking hours at home interacting in Finnish with his parents and siblings, and in English with his au-pair; he also heard his parents interact with the au-pair in English. Eetu did not attend a childcare provision during the data collection period. Information about his lexical proficiency in both languages is missing. Eetu's MLU, as captured on video, is 1.9 in his Finnish $(\mathrm{n}=228)$ and 2.0 in his English $(\mathrm{n}=176)$ utterances. Although this suggests dominance in English, his parents report that Eetu was clearly dominant in Finnish and only spoke English with his au-pair who is present in all the video recordings. Eetu was recorded between the ages of 2;9 and 2;11 for the total of 122 minutes.

\subsection{Sampling}

In Sadie's audio-video corpus recorded as part of a larger project, there are 156 half-hour recordings available from the ages of 0;9-2;5 but this study focused only on 26 half-hour recordings, about one per week, all spanning the 
period of five months. The data chosen for the analysis overlap to some extent with the data discussed in another CS study (Gaskins et al. 2019) except for three changes. First, in this study diary data were used only for Traceback analysis and not as source of bilingual constructions. Second, recordings from below the age of two are used only to trace back schemas rather than as a source of CS. Third, we supplement Sadie's CS data with eight extra recordings from above the age of two which did not make part of the data discussed by Gaskins et al. (2019). The interactions were captured in naturalistic settings, at mealtime and subsequent playtime, with either the Polish-speaking mother $(\mathrm{n}=10)$ or the English-speaking father $(n=7)$ or both parents present $(n=9)$. The part of the corpus used in this study consists of 1,734 multi-word turns of which 184 (11\%) were mixed and all of which were used for the Traceback analysis.

In Sylvie's audio corpus, recorded as part of a larger project, there are 360 halfhour recordings available from the ages of 2;4-3;10 but this study focused only on 12 recordings about $3-4$ per week, recorded over a period of a month. The entirety of Sylvie's CS data is the focus of another CS study (Quick Endesfelder et al. 2018b). The recordings were made at home, during free play, meals and while reading a book, with both parents present which resulted in a bilingual context. The part of corpus used here captures the total of 2,775 multi-word turns of which 253 (9\%) were mixed and all of which were used for the Traceback analysis.

Eetu was recorded sporadically between the ages of 2;9-2;11 during naturalistic interactions when playing games, such as naming pictures on cards, and doing crafts with the au-pair and at least one of his siblings. The whole corpus captures the total of 356 multi-word turns of which 141 (40\%) were mixed and all of which were used for the Traceback analysis.

All transcription was manual and the analysis word-based. Word-internal mixes were coded as bilingual: whether they were included in the frame or the slot, the construction was treated as bilingual.

\subsection{Languages}

The three children all had English, a West Germanic language, in their input. Additionally, Sylvie was exposed to German which shares significant portions of vocabulary roots with English, its close relative. Sadie's 'other' language, Polish, is more remotely related to English: although they have both originated from the Indo-European family, Polish is a West Slavic language and as such considered a more distant relative of English than German. Eetu's 'other' language is Finnish, a Finno-Ugric language which is from the Uralic language family and thus also relatively distant from English. 


\subsection{Analysis}

Once the corpus was transcribed, the nature of constructions was established using the Traceback method developed for use on densely sampled corpora of recorded speech where constructions are traced back to those recorded in prior videotaped interactions to determine which part of the construction is a frame and which a slot (Dąbrowska and Lieven 2005; Lieven et al. 2009; Quick Endesfelder et al. 2018a). In our study, four categories were chosen in the coding process: 1) other; 2) chunk; 3) PS unit; 4) chunk + chunk. The first occurrence of a construction was marked as 'other' if it was the first occurrence of that specific construction in the corpus (e.g. Everybody kask 'helmet'). The moment the same construction was used again, as long as it was divided from the first instance by another conversational turn, it was considered a 'chunk'. If an element kept recurring in the data with a range of words attached to it, it was considered a 'PS unit' (e.g. X helmet). If one chunk was combined with another, it was placed within the 'chunk-chunk' category (e.g. aber ein 'but a' + little bit). The first analyses were concerned with the amount of CS in the data; the most frequently used schemas; language preference for frames and elements filling the slots; any common and disparate patterns used. The data were also coded for mean length of utterance (MLU) in words. We excluded all one-word utterances which contained only one orthographic word from our MLU calculations. This was done following an observation of low numbers of word-internal mixes in PolishEnglish and Finnish-English but not English-German acquisition and including them in MLU counts would have made comparisons between language pairs problematic.

\subsection{Summary of differences}

It is important to emphasize the fact that the three children observed in this study differ substantially in their profiles. Differences are notable not only in terms of the two languages they were exposed to but also in how and when they heard their two languages, the age of exposure to both of their languages, their dominance levels, and the family language policy. The recordings used in this study capture slightly different developmental stages and the analysis draws on different data available: while in the case of Sylvie and Eetu the Traceback method is restricted to the recordings, in Sadie's case it is extended to the diary data. We are interested to see, however, if the three children shared any patterns of use despite the many differences in their profiles. 


\section{Results}

\subsection{Construction types in CS utterances}

Our first analysis focused on the levels of schematicity in all CS utterances across the three data sets. The data were classified according to four categories, with the results showing heavy reliance on constructions with single and multiword slot fillers in all three children studied and regardless of the differences in their profiles: if $P S$ and chunk + chunk constructions were added up for each child, the proportions of such semi-productive schemas were very close ( $\mathrm{n}=109,64 \%$ in Sadie; $\mathrm{n}=161,63 \%$ in Sylvie and $\mathrm{n}=86,61 \%$ in Eetu). Low numbers of tokens in Sadie's other category, compared to her peers, may have resulted from access to earlier data for Sadie's development which reduced the numbers of constructions which could not be traced back to any prior language used. Low numbers of tokens in her chunk + chunk category could be explained by the fact that Sadie was the youngest of the three participants and her MLUs were the lowest (e.g. her bilingual MLU was 2.79 compared to Sylvie's 3.8 and Eetu's 3.2) which in turn meant that her slots were more likely to be filled with individual words rather than multi-word stretches of speech.

Figure 2 additionally shows that in each child relatively high numbers of CS constructions were chunks that had not been assembled in the moment of speech but produced holistically $(\mathrm{n}=60,32 \%$ in Sadie; $\mathrm{n}=30,12 \%$ in Sylvie; $\mathrm{n}=35,25 \%$ in Eetu). These tokens were derived from a smaller pool of types: in Sadie's speech there were 25, in Sylvie's 22 and in Eetu's 20 types of bilingual chunks. Their recycled use on video does not imply that they had not been assembled productively when put together for the first time. It merely confirms that the repeated processing of the non-target like construction through access and retrieval was a less costly, and therefore sometimes a preferred route to selective handling of the linguistic material involved.

\subsection{Language distribution across the frames}

At the next stage, we analysed the distribution of languages in the frames of PS units across the children's two languages (see Figure 3). The fixed element and the slot were coded by language as either English or Polish/German/Finnish. Results show that across all code-switched PS units all children had a clear preference for using frames mostly in one of their two languages ( $\mathrm{n}=83,81 \%$ of all Sadie's frames were English; $\mathrm{n}=122,88 \%$ Sylvie's were German; $\mathrm{n}=66,87 \%$ Eetu's were 


\section{English-Polish}

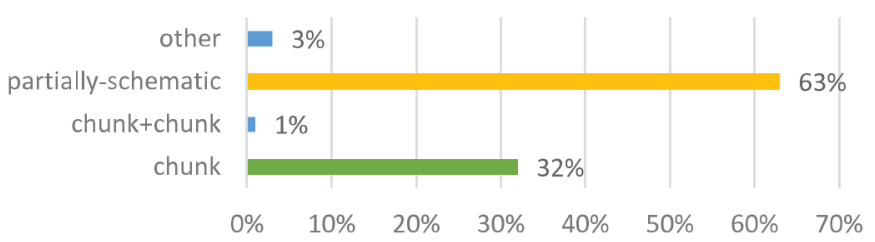

\section{English-German}

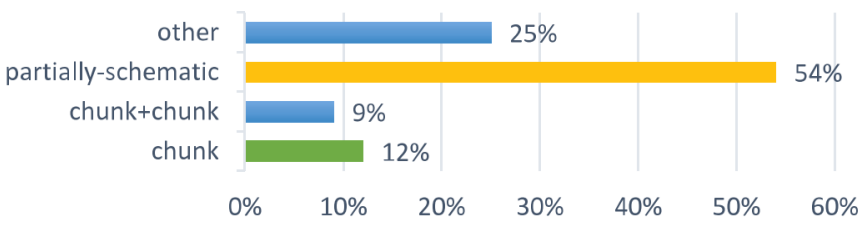

English-Finnish

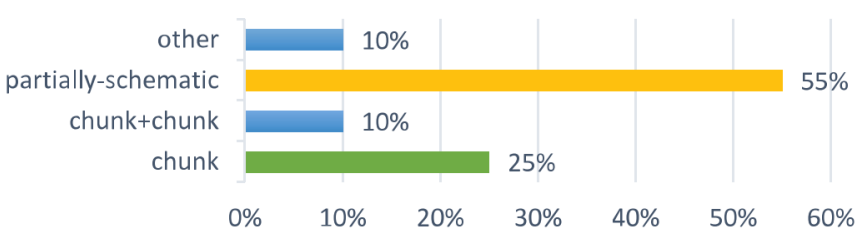

Figure 2: Levels of schematicity in CS utterances.

English). Beyond this, further analysis of the same units shows that the pattern used by far most commonly by all three children involved combining a monolingual frame from one language with an item from another language in the productive slot in the schema ( $n=89,98 \%$ in Sadie; $n=128,93 \%$ in Sylvie; $n=73,94 \%$ in Eetu). This shows that collocational bonds between the component parts of the frames were more likely to become entrenched between words from the same language and not between words from two different languages.

This approach allowed us to highlight the differences in the use of bilingual chunks and bilingual frames. Sadie had only one bilingual frame (Daj mi that $X$ 'Given me that X') which was built around a frozen chunk produced previously and which was responsible for two tokens of mixing (2\%); Sylvie had 14 types of bilingual frames (e.g. Ich like $X$ 'I like X) of which five types were built around frozen chunks she has produced earlier on video, all responsible for 10 tokens of mixing (7\%) and Eetu had five types of bilingual frames (e.g. Me tosi X 'Me very X'), four of which were linked to 

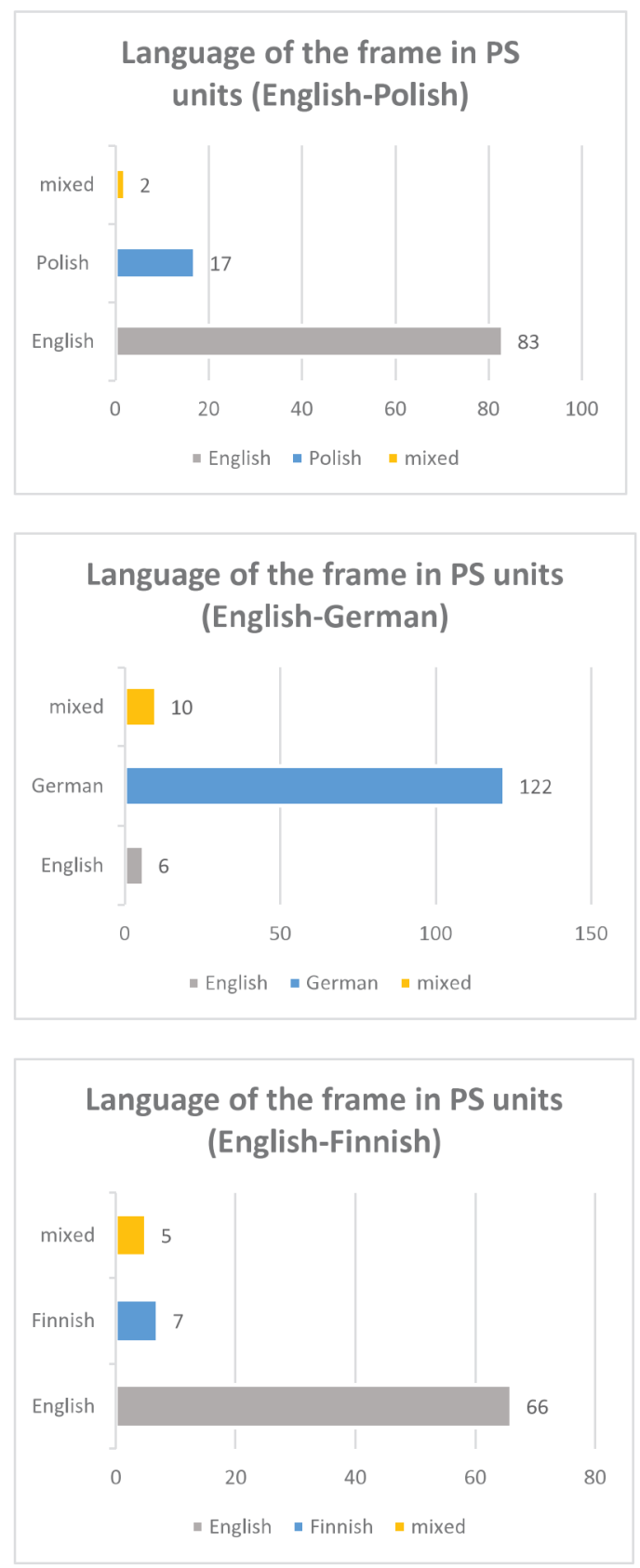

Figure 3: Language distribution in the frames of PS units for all three children.

Bereitgestellt von | Universitaetsbibliothek Leipzig Angemeldet Heruntergeladen am | 20.05.19 09:46 
previously produced chunks, all responsible for five tokens of mixing $(6 \%)$ (see Appendix 3). This observation confirms two things. First of all, the numbers of bilingual frames in all children's PS units are a smaller subset of bilingual chunks (25 types of bilingual chunks vs. one type of bilingual frame in Sadie; 22 types of bilingual chunks vs. 14 types of bilingual frames in Sylvie; 20 types of chunks vs. five types of bilingual frames in Eetu). This pattern recurs in all three datasets, suggesting that it is important in the story of each of the three children. Seeing fewer bilingual frames than bilingual chunks confirms some filtering out of mixing between step 2 and step 3 of our model with only some mixing filtered through to PS. This also lends support to the view that the construction of frames is dynamic, and that CS is sensitive to the frequency and similarity of low-scope forms. Furthermore, a question arises as to why some of the bilingual chunks were additionally creatively combined with slot fillers in speech, particularly that of Sylvie's. Is there anything that these bilingual frames produced by all three children have in common which could help us to understand their further recycling in more complex constructions?

Further analysis confirmed that many examples of the bilingual frames produced contained words which are phonologically close in both of the child's languages. In Sadie's speech, for example, the Polish word $m i$ 'me' in the schema Daj mi that $X$ is homophonous and synonymous with the English me and it is that word which acted as a bridge between the Polish daj 'give' and the English that. In Sylvie's speech, in a schema $X$ for mir, for example, the slot is followed by the English word for and the German word mir 'me'. Here, it could be the phonological proximity between the words for and für 'for' and possibly mir and me which could explain the repeated processing of the mixed frame in this case. In the bilingual frames used by Eetu, the first person pronoun me is phonologically close to the respective Finnish pronoun (min $\ddot{a} \sim m \ddot{a}(\ddot{a})$ ). However, Eetu also has two bilingual schemas Tosi $X$ eyes 'Very $\mathrm{X}$ eyes' and $X$ is vessassa ' $\mathrm{X}$ is in the toilet', which do not include any homophonous elements. In the next section we will suggest a UB explanation for why we believe the frozen bilingual chunks of these constructions had not been filtered out in use and instead had given rise to creative PS combinations.

\section{Discussion}

In this UB study of early CS we have examined the total of 582 CS multi-word combinations collected from three children exposed to English-Polish $(n=188)$, 
English-German ( $\mathrm{n}=253)$ and English-Finnish $(\mathrm{n}=141)$ in their input. We traced them back to the same children's 4,869 monolingual constructions to establish whether they were frozen chunks, PS units or 'other' (English-Polish $\mathrm{n}=1$,738; English-German $\mathrm{n}=2,775$; English-Finnish $\mathrm{n}=356$ ). In our discussion, we will first address the question regarding any similarities in the use of the CS patterns. First of all, in all three children, most CS constructions were either classed as chunks ( $\mathrm{n}=60,32 \%$ in Sadie; $\mathrm{n}=30,12 \%$ in Sylvie; $\mathrm{n}=35$, $25 \%$ in Eetu) or traced back to PS units, with one or more items filling the slot ( $\mathrm{n}=109,64 \%$ in Sadie; $\mathrm{n}=161,63 \%$ in Sylvie and $\mathrm{n}=92,65 \%$ in Eetu). This confirms earlier observations of Quick Endesfelder et al. (2018a) that most of the children's bilingual constructions can be accounted for by reference to low-level schemas, only partly productive, and partly recycled from language automated through prior use. Our study confirms that this is the case not only in the acquisition of English and German but across the three language combinations we studied and despite significant differences in the three children's language acquisition profiles.

When only PS units were analysed there was a clear preference for using monolingual frames (98\% English in Sadie; 93\% German in Sylvie; 94\% English in Eetu) and combining them with slot fillers from another language. This is important in at least two ways. First, it confirms that slot productivity can account for only some of the CS: such combinations of monolingual frames with slot fillers from another language amount to 53\% of all of Sadie's, $50 \%$ of Sylvie's and 48\% all of Eetu's mixed constructions recorded in the data, whether frozen or PS (see also Gaskins et al. 2019). Second, while children preferred to use frames in one of their languages with slot fillers in another, the opposite trend was also observed: $17 \%$ of Sadie's frames were Polish; $4 \%$ of Sylvie's were English and 9\% of Eetu's frames were Finnish. This is in line with Müller et al. (2015) who showed that children mix functional items (typically equivalent to frames) bi-directionally, generally from their stronger to their weaker language but also in the opposite direction. In fact, in Eetu's case, most frames (85\%) were derived from English, his weaker language but one which was addressed at him in the context of interactions. Our data thus show that the distinction between frames and slot fillers does not correspond accurately with distinctions between languages, at least if we adopt a UB approach to data analysis.

The observation that higher proportions of CS occurred in chunks than within the frames of PS units also confirms that between step 2 and step 3 of our model, some of the bilingual combinations had been filtered out. As suggested earlier, we believe that this may have happened due to higher levels of attention in the production of PS units, as compared with lower levels of attention used in the production of recyclable chunks. This change may also have been reinforced by 
separation of the children's languages in the input which is likely to support the creation of bonds between words from the same language and not between words from two different languages. However, the latter claim is difficult to support in this study as the extent of language separation was not comparable across the three data sets: Sadie's and Sylvie's parents used the OPOL strategy while Eetu heard Finnish from his family and English from his au pair who occasionally switched into Finnish. This aspect of input should be carefully controlled for in future studies. Ultimately, what was left at stage 3 was a pool of bilingual frames which revealed phonological proximity of the words involved (e.g. in Daj mi X 'give me X' the frame contains the word mi ' $m e$ ' which is homophonous in Polish and English). We believe, however, that any generalisations based on the genealogy of the languages which emerge from this study should be treated with a grain of salt due to the great differences in the data available and in the three children's language profiles.

The observation that there is less CS in bilingual frames in the data of our Polish-English and Finnish-English participants corresponds with what we know about the genealogical distance between English on the one hand and Polish and Finnish on the other. Specifically, in Eetu's CS repertoire, only two instances of bilingual frames can be explained by phonological overlap. This is in line with Frick's study of adult CS (2013) which shows that bilingual homophony can facilitate adult CS in Estonian and Finnish but it does not explain it all. Moreover, as Sylvie, our English-German participant, had the highest numbers of bilingual frames, this suggests that genealogical proximity between English and German must have been at play in facilitating repeated processing of those bilingual chunks. This is further supported by the observation that these proportions were even higher in her English-German peer Tim (Quick Endesfelder et al. 2018a). Tim's bilingual frames were indeed very similar to those used by Sylvie, represented in highest numbers by Ich want $X$ 'I want $X$ ', Und this $X$ 'And this $X$ ', Und this is $X$ 'And this is $X$ ', and other schemas which relied on areas of phonological proximity between English and German. English and German share a pool of words which are similar in form, meaning and spelling and thus have been shown to support each other's acquisition in child language (e.g. nouns: Schelletter 2002; nouns and verbs: Schelletter 2005). Within the network perspective, words which are phonologically close receive double input and are therefore well entrenched (Bybee 2001; Schmid 2017); this early entrenchment also means that they are likely to become interconnected early in acquisition and therefore are more likely to be easily co-activated in the moment of speech, leading to more instances of CS. This would explain why, after filtering out some mixing at step 3 of our model, all three children continued to mix in areas of phonological overlap but that in Sylvie's (and Tim's) data there was more of such mixing than is Sadie's and Eetu's speech. In earlier research literature, CS 
facilitated by phonological overlap is well documented and broadly referred to as triggering (for a review see: Clyne 2003).

The data provided in this study largely support our CS model although denser recordings, and child language acquisition profiles carefully controlled for the extent to which the two languages are separated in the input, would be necessary to capture more accurately the link between bilingual frames and bilingual chunks. We predict that in contexts where the child's two languages are delivered separately, children will filter out some of their CS by step 3 and this is largely borne out by the data examined in this study. However, this is not supported by the observation that Tim had more bilingual frames than bilingual chunks (Quick Endesfelder et al. 2018a). One possible explanation for high numbers of bilingual frames observed in Tim's data is that his corpus was much denser than the corpora we discussed here and therefore, while our study was more likely to capture differences in types of CS utterances, Tim's corpus was more likely to reveal differences in tokens. As Tim's bilingual frames also revolve around areas of phonological proximity, it is likely that Tim had also filtered out some CS by the time he started constructing longer PS units. However, once bilingual frames were formed, their frequent recycling must have inflated the token numbers of CS utterances in Tim's corpus.

\section{Conclusion}

In conclusion, in this study we have shown that early CS can be explained considering all three children's own usage patterns. We have confirmed that the patterns observed in the switching between English and German also hold for English-Polish and English-Finnish: that the vast majority of CS can be explained by low-level schemas, such as frozen chunks and PS units, without the need to refer to underlying linguistic representations. We have proposed a new UB model of early switching which explains why not all mixing results from productivity of constructions. This model shows that while some frozen bilingual chunks may be produced as a result of compromised levels of attention and thus filtered out in contexts where the two languages are separated in the input, those which filter through to the frames of PS units can be explained by genealogical proximity of the languages spoken by the child, with English-German revealing more interaction than English-Polish or English-Finnish. 


\section{References}

Bartolotti, James \& Viorica Marian. 2013. Bilingual memory: Structure, access and processing. In Jane Altarriba \& Ludmila Isurin (eds.), Memory, language, and Bilingualism. Camridge: CUP.

Bernardini, Petra \& Suzanne Schlyter. 2004. Growing syntactic structure and code-mixing in the weaker language: The ivy hypothesis. Bilingualism: Language and Cognition 7(1). 49-69.

Bybee, Joanne. 2001. Phonology and language use. Cambridge: Cambridge University Press.

Cantone, Katia Francesca. 2007. Code-switching in bilingual children. Dordrecht: Springer.

Clyne, Michael. 2003. Dynamics of language contacts. Cambridge: CUP.

Dąbrowska, Ewa \& Elena Lieven. 2005. Towards a lexically specific grammar of children's question constructions. Cognitive Linguistics 16(3). 437-474.

Deuchar, Margaret \& Suzanne Quay. 2000. Bilingual acquisition. Theoretical implications of a case study. New York: OUP.

Deuchar, Margaret \& Marylin Vihman. 2005. A radical approach to early mixed utterances. International Journal of Bilingualism 9(2). 137-157.

Frick, Maria. 2013. Emergent Bilingual Constructions. Finnish-Estonian Code-switching in Interaction. Doctoral dissertation, University of Helsinki.

Gaskins, Dorota, Ad Backus \& Antje Quick Endesfelder. 2019. Slot-and-frame schemas in the language of a Polish- and English-speaking child: the impact of usage patterns on the switch placement. Languages 4. 8. doi:10.3390/languages4010008.

Gawlitzek-Maiwald, Ira \& Rosemary Tracy. 1996. Bilingual Bootstrapping. Linguistics 34(5). 901-926.

Keren-Portnoy, Tamar. 2006. Facilitation and practice in verb acquisition. Journal of Child Language 33. 487-518.

Lanza, Elizabeth. 1997. Language mixing in infant Bilingualism. A sociolinguistic perspective. Oxford: Oxford University Press.

Lieven, Elena, Julian Pine \& Gillian Baldwin. 1997. Lexically-based learning and early grammatical development. Journal of Child Language 24. 187-220.

Lieven, Elena, Dorothè Salomo \& Michael Tomasello. 2009. Two-year-old children's production of multiword utterances: a usage-based analysis. Cognitive Linguistics 20(3). 481-507.

Müller, Natascha, Laia Arnaus Gil, Nadine Eichler, Jasmin Geveler, Malin Hager, Veronika Jansen, Marisa Patuto, Valentina Repetto \& Schmeißer. Anika. 2015. Code-Switching: Spanisch, Italienisch, Französisch. Eine Einführung [Code-switching: Spanish, Italian, French. One Approach]. Tübingen: Narr.

Myers-Scotton, Carol. 1993 [1997]. Duelling languages: Grammatical structure in codeswitching (1997 edition with a new Afterword). Oxford: Clarendon Press.

Myers-Scotton, Carol \& Janice Jake. 2001. Explaining aspects of code-switching and their implications. In J. L. Nicol (ed.), One mind, two languages: Bilingual language processing. Massachusetts: Blackwell Publishers.

Namba, Kazuhiko. 2012. English-Japanese code-switching and formulaic language: A structural approach to bilingual children's interactions. Saarbrücken: LAP LAMBERT Academic Publishing.

Pert, Sean. 2007. Bilingual language development in Pakistani heritage children in Rochdale UK: Intrasentential codeswitching and the implications for identifying specific language impairment. Newcastle University PhD thesis. Available at http://hdl.handle.net/10443/ 2230 
Pfaff, Carol. 2011. Changing patterns of language mixing in a bilingual child. In P. Jordens (ed.), Bilingualism and Migration. Studies on language acquisition, 97-122. Berlin: De Gruyter Mouton.

Quick Endesfelder, Antje, Ad Backus \& Elena Lieven. 2018. Partially schematic constructions as engines of development: Evidence from German-English bilingual acquisition. Placing meaning, usage and mind at the core of contact-induced variation and change. In Eline Zenner, Ad Backus \& Esme Winter-Froemel (eds.), Cognitive contact linguistics. Placing usage, meaning and mind at the core of contact-induced variation and change. Berlin: De Gruyter.

Quick Endesfelder, Antje, Elena Lieven, Ad Backus \& Michael Tomasello. 2018b. Constructively combining languages. The use of code-mixing in German-English bilingual child language acquisition. Linguistic Approaches to Bilingualism 8(3). 393-409.

Quick Endesfelder, Antje, Elena Lieven, Melinda Carpenter \& Michael Tomasello. 2018a. Identifying partially schematic units in the code-mixing of an English and German speaking child. Linguistic Approaches to Bilingualism 8(4). 477-501.

Quick Endesfelder, Antje, Elena Lieven \& Michael Tomasello. 2016. Mixed NPs in GermanEnglish and German-Russian bilingual children. In Justyna Robinson \& Monika Reif (eds.), Cognitive perspectives on bilingualism. Trends in Applied Linguistics (TAL). Berlin: de Gruyter.

Schelletter, Christina. 2002. The effect of form similarity on bilingual children's lexical development. Bilingualism: Language and Cognition 5. 93-107.

Schelletter, Christina. 2005. Bilingual children's lexical development: Factors affecting the acquisition of nouns and verbs and their translation equivalents. Proceedings of the 4 th International Symposium on Bilingualism. Somerville, MA: Cascadilla Press.

Schmid, Hans Jörg. 2017. A framework for understanding linguistic entrenchment and its psychological foundations. In Hans Jörg Schmid (eds.), Entrenchment and the psychology of learning: How we reorganise and adapt linguistic knowledge. Washington, DC: APA and Walter De Gruyter.

Schmidt, Richard. 2010. Attention, awareness and individual differences in language learning. In Wai Meng Chan, Seo Won Chi, Kwee Nyet Cin, Johanna Istanto, Masanori Nagami, Jyh Wee Sew, Titima Suthiwan \& Izumi Walker (eds), Proceedings of CLaSIC 2010. Singapore: Centre for Language Studies.

Stoll, Sabine, Kirsten Abbot-Smith \& Elena Lieven. 2009. Lexically restricted utterances in Russian, German, and English child-directed speech. Cognitive Science 33. 75-103.

Tomasello, Michael. 2003. Constructing a language: $A$ usage-based theory of language acquisition. Cambridge: Harvard University Press.

Walsh, Michael, Bernd Möbius, Travis Wade \& Hinrich Schütze. 2010. Multilevel exemplar theory. Cognitive Science 34. 537-582. 


\section{Appendix 1}

\subsection{Sadie's total inventory of frozen chunks}

$\begin{array}{ll}\text { example } & \text { translation } \\ \text { alright pies } & \text { alright dog } \\ \text { woda mummy } & \text { water mummy } \\ \text { one truskawkis } & \text { one strawberries } \\ \text { two ciasto } & \text { two cake } \\ \text { where other one owcas } & \text { where other one sheep } \\ \text { I don't want it new zdjęcie } & \text { I don't want it new photo } \\ \text { and to } & \text { and this } \\ \text { daj mi that } & \text { give me that } \\ \text { prosze mummy } & \text { please mummy } \\ \text { eat mleko } & \text { eat milk } \\ \text { no ziemniaczki } & \text { no potatoes } \\ \text { more kredę } & \text { more chalk } \\ \text { no chcę } & \text { no [I] want } \\ \text { kuku baby } & \text { peepo baby } \\ \text { more matpa } & \text { more monkey } \\ \text { more pies } & \text { more dog } \\ \text { other one kaczki } & \text { other one ducks } \\ \text { where other one kaczkis } & \text { where other one ducks } \\ \text { more motyl } & \text { more butterfly } \\ \text { prosze mummy } & \text { please mummy } \\ \text { where other one misiu } & \text { where other one teddy } \\ \text { daj breakfast } & \text { give breakfast } \\ \text { where other one auto } & \text { where other one car } \\ \text { daddy domu } & \text { daddy home } \\ \text { my kon } & \text { my horse } \\ \end{array}$

\subsection{Sylvie's total inventory of frozen chunks}

example
das one
die is juicy
mammi die slipen doch nich
du bist ein frog

\author{
translation \\ this one \\ this is juicy \\ mummy, they sleep not \\ you are a frog
}




ein big one
ein dress
ein goat
ein oster bunny
heissen water
ich bin nich stuck
ich brauche mein knife
ich do it ich aber du nicht
ich hab ducks
ich like das
kein lollipop
mehr water
nee dis one
noch ein bird
noch dis one
und dis one
wo is mein torches

a big one
a dress
a goat
an Easter bunny
hot water
I am not stuck
I bring my knife
I do it I but you not
I have ducks
I like this
no lollipop
more water
no this one
more one bird
more this one
and this one
where is my torches

\subsection{Eetu's total inventory of frozen chunks}

example
kato pink panther
me punaista
tosi iso eyes
an(d) tässä
Maria me nukun tässä.
and tässä
and me susi
it is pik-
tämä on (v)ihreä and
me näytän
on oranssi this
this go Rikki
me saksaa(n) this
not me tosi kylmä
en me halua this Maria
I go puistossa
an(d) tässä
me susi

\author{
translation \\ look pink panther \\ me red \\ very big eyes \\ and here \\ Maria me sleep-1SG here \\ and here \\ and me wolf \\ it is undies \\ this is green and \\ me show-1SG \\ is orange this \\ this go broken \\ me cut-(1SG) this \\ not me very cold \\ no-1SG want this Maria \\ I go park-INE \\ and here \\ me wolf
}


Maria me autan

me talo
Maria me help-1SG

me house

\section{Appendix 2}

\subsection{Sadie's total inventory of partially schematic constructions}

$\begin{array}{lll}\text { example } & \text { translation } & \text { language } \\ \text { And } X & - & \text { English } \\ \text { Come on, } X & - & \text { English } \\ \text { Daj mi that } X & \text { Give me } X & \text { bilingual } \\ \text { Daj } X & \text { Give } X & \text { Polish } \\ \text { Domu, } X & \text { Home, } X & \text { Polish } \\ \text { Everybody } X & - & \text { English } \\ \text { Go away, } X & - & \text { English } \\ \text { Got } \text { me } X & - & \text { English } \\ \text { I don't want } X & - & \text { English } \\ \text { I don't want it } X & - & \text { English } \\ \text { I want it } X & - & \text { English } \\ \text { Jeszcze } X & \text { More } X & \text { Polish } \\ \text { Kuku } X & \text { Peepo } X & \text { Polish } \\ \text { More other one } X & - & \text { English } \\ \text { More } X & - & \text { English } \\ \text { My } X & - & \text { English } \\ \text { Where other one } X & - & \text { English } \\ \text { Now where's } X & - & \text { English } \\ \text { Oh no, } X & - & \text { English } \\ \text { One two } X & - & \text { English } \\ \text { One } X & - & \text { English } \\ \text { Other one } X & - & \text { English } \\ \text { Other one } X \text { please } & - & \text { English } \\ \text { Other } X & - & \text { English } \\ \text { Please } X & - & \text { English } \\ \text { Proszę } X & - & \text { Polish } \\ \text { To jest } X & - & \text { English } \\ \text { Too many } X & - & \end{array}$




$\begin{array}{lll}\begin{array}{l}\text { Two little } X \text { sitting on } \\ \text { the wall }\end{array} & - & \text { English } \\ \text { Two } X & - & \text { English } \\ \text { Two } X \text { s } & - & \text { English } \\ \text { What you doing, } X & - & \text { English } \\ \text { Where is other } X & - & \text { English } \\ \text { Where is } X & - & \text { English } \\ X \text { domu } & X, \text { home! } & \text { Polish } \\ X \text { horse } & - & \text { English } \\ X \text { is } & - & \text { English } \\ X \text { on the table } & - & \text { English } \\ X \text { there } & - & \text { English } \\ X \text { tutaj } & X \text { here } & \text { Polish } \\ X \text { look } & - & \text { English } \\ X \text {, tata } & X, \text { daddy } & \text { Polish } \\ X \text { s } & - & \text { English } \\ \text { Yes } X & - & \text { English } \\ \text { Where is other } X & - & \text { English } \\ \text { Where is } X & - & \text { English } \\ \text { Where other one } X & - & \text { English } \\ \text { Naughty } X & - & \text { English } \\ \text { No } X & - & \text { English }\end{array}$

\subsection{Sylvie's total inventory of partially schematic constructions}

$\begin{array}{lll}\text { example } & \text { translation } & \text { language } \\ \text { Aber das } X & \text { But this X } & \text { German } \\ \text { Aber die sind } X & \text { But they are X } & \text { German } \\ \text { Aber ich habe } X & \text { But I have X } & \text { German } \\ \text { Aber ich } X & \text { But I X } & \text { German } \\ \text { Aber jetzt } X & \text { But now X } & \text { German } \\ \text { Alle beide } X & \text { All both X } & \text { German } \\ \text { And } X & - & \text { English } \\ \text { Bin } \text { ein } X & {[\mathrm{I}] \text { am a/an X }} & \text { German }\end{array}$




\begin{tabular}{|c|c|c|}
\hline$D a$ is $X$ & There is $\mathrm{X}$ & bilingual \\
\hline Da sind die $X$ & There are the $\mathrm{X}$ & German \\
\hline Da sind $X$ & There are $\mathrm{X}$ & German \\
\hline Da unten $X$ & There down $\mathrm{X}$ & German \\
\hline Darf ich auch $X$ & May I too X & German \\
\hline Das is $X$ & This is $\mathrm{X}$ & bilingual \\
\hline Das sind $X$ & There are $\mathrm{X}$ & German \\
\hline Das X & This $\mathrm{X}$ & German \\
\hline Der elephant $X$ & The elephant X & bilingual \\
\hline Der X clock & The $\mathrm{X}$ clock & bilingual \\
\hline Die haben keine $X$ & They have no $\mathrm{X}$ & German \\
\hline Die ist $X$ & It is $\mathrm{X}$ & German \\
\hline Die $X$ nicht & The $\mathrm{X}$ not & German \\
\hline Du bist $X$ & You are $\mathrm{X}$ & German \\
\hline $\operatorname{Ein} X$ & $\mathrm{~A} / \mathrm{an} \mathrm{X}$ & German \\
\hline Ein $X$ one & $\mathrm{A} /$ An $\mathrm{X}$ one & bilingual \\
\hline For $X$ & - & English \\
\hline Guck dort X & Look there $\mathrm{X}$ & German \\
\hline Guck mal X & Look X & German \\
\hline$H a b X$ & [I] have X & German \\
\hline Hast du ein $X$ & Have you a $\mathrm{X}$ & German \\
\hline Hast $d u X$ & Have you $\mathrm{X}$ & German \\
\hline Hier ist der $X$ & Here is the $\mathrm{X}$ & German \\
\hline Hier X & Here X & German \\
\hline I like nicht $X$ & I like not $\mathrm{X}$ & bilingual \\
\hline Ich bin $X$ & I am X & German \\
\hline Ich brauche $X$ & I bring $\mathrm{X}$ & German \\
\hline Ich hab noch $X$ & I have another $\mathrm{X}$ & German \\
\hline Ich hab X & I have $\mathrm{X}$ & German \\
\hline Ich like $X$ & I like $\mathrm{X}$ & bilingual \\
\hline Ich mach $X$ & I make $X$ & German \\
\hline Ich möchte X haben & I want $\mathrm{X}$ to have & German \\
\hline Ich möchte $X$ & I want $\mathrm{X}$ & German \\
\hline I'm $X$ & - & English \\
\hline Ja X & Yes $\mathrm{X}$ & German \\
\hline Jetzt bin ich $X$ & Now I am X & German \\
\hline Jetzt hab ich $X$ & Now I have $\mathrm{X}$ & German \\
\hline
\end{tabular}




\begin{tabular}{|c|c|c|}
\hline Jetzt $X$ & Now $\mathrm{X}$ & German \\
\hline Kommt X & Comes X & German \\
\hline Lass $X$ & Let $\mathrm{X}$ & German \\
\hline Look $X$ & - & English \\
\hline Meins X & Mine's X & German \\
\hline Mit dir $X$ & With you X & German \\
\hline Mit $X$ & With X & German \\
\hline Möchte nicht $X$ & [I] want not X & German \\
\hline Möchte X bitte & [I] want X please & German \\
\hline Like nicht $X$ & [I] like not X & bilingual \\
\hline Zwei $X$ & Two X & German \\
\hline Möchte auch $x$ & [I] want also X & German \\
\hline Müssen wir $X$ & Must we $\mathrm{X}$ & German \\
\hline Nein das is $X$ & No this is $\mathrm{X}$ & bilingual \\
\hline Nein $X$ & No, $\mathrm{X}$ & German \\
\hline Nicht $X$ & Not X & German \\
\hline Noch ein $X$ & Another X & German \\
\hline Noch $X$ bei dir & Still $\mathrm{X}$ with you & German \\
\hline This is $X$ & - & English \\
\hline This one $X$ & - & English \\
\hline Und $d a$ is $X$ & And there is $\mathrm{X}$ & bilingual \\
\hline Und dann X & And then $\mathrm{X}$ & German \\
\hline Und das is $X$ & And this is $\mathrm{X}$ & bilingual \\
\hline Und $\operatorname{der} X$ & And he $\mathrm{X}$ & German \\
\hline Und $d u$ nicht $X$ & And you not $\mathrm{X}$ & German \\
\hline Und ein $X$ & And a/an $\mathrm{X}$ & German \\
\hline Und eine $X$ & And a/an $\mathrm{X}$ & German \\
\hline Und noch $X$ & And another $\mathrm{X}$ & German \\
\hline Und this one $X$ & And this one $\mathrm{X}$ & bilingual \\
\hline Und wo ist $X$ & And where is $\mathrm{X}$ & German \\
\hline Und $X$ & And $X$ & German \\
\hline Wieder X & Again X & German \\
\hline Wir haben $X$ & We have $\mathrm{X}$ & German \\
\hline Wo is $X$ & Where is $\mathrm{X}$ & bilingual \\
\hline$X d a$ & $\mathrm{X}$ there & German \\
\hline$X$ do it & - & English \\
\hline$X$ for mir & $X$ for me & bilingual \\
\hline
\end{tabular}




$\begin{array}{lll}X \text { machen } & \mathrm{X} \text { to make } & \text { German } \\ X \text { noch } & \mathrm{X} \text { another/too } & \text { German } \\ X \text { von } \text { mir } & \mathrm{X} \text { from me } & \text { German }\end{array}$

\subsection{Eetu's total inventory of partially schematic constructions}

$\begin{array}{lll}\text { example } & \text { translation } & \text { language } \\ \text { And } \text { me tosi } X & \text { And me very X } & \text { bilingual } \\ \text { And } \text { me } X & - & \text { bilingual } \\ X \text { punaista } & \text { X red } & \text { Finnish } \\ \text { And } X & - & \text { English } \\ \text { Come on } X & - & \text { English } \\ \text { Go } X & - & \text { English } \\ \text { Here } \text { me } X & - & \text { English } \\ \text { It is } X & - & \text { English } \\ \text { missä } X & \text { where } X & \text { Finnish } \\ \text { You } X & - & \text { English } \\ X \text { here } & - & \text { English } \\ \text { Kato } \text { me } X & \text { Look me X } & \text { bilingual } \\ \text { Kato } X & \text { Look X } & \text { Finnish } \\ \text { Me go } X & - & \text { English } \\ \text { Me } X & - & \text { English } \\ \text { Me } X \text { this } & - & \text { English } \\ X \text { auto } & \text { X car } & \text { Finnish } \\ \text { Miksi } X & \text { Why X } & \text { Finnish } \\ \text { No } X & - & \text { English } \\ \text { Not } X & - & \text { English } \\ \text { Kuka } X & \text { Who X } & \text { Finnish } \\ \text { Yes } X & - & \text { English } \\ \text { This is } X & - & \text { English } \\ \text { This } X & - & \text { English } \\ \text { Tosi } X \text { eyes } & - & \text { bilingual } \\ X \text { go } & \text { English } \\ X \text { here } & \text { English } \\ X \text { is } & - & \text { English }\end{array}$




$\begin{array}{lll}X \text { it is } & - & \text { English } \\ X \text { this } & - & \text { English } \\ \text { Ei } X & \text { No } X & \text { Finnish } \\ X \text { Pink Panther } & - & \text { English } \\ X \text { is vessassa } & \mathrm{X} \text { is in the toilet } & \text { bilingual }\end{array}$

\title{
Appendix 3
}

\subsection{Sadie's total inventory of bilingual frames}

\author{
example translation
}

Daj mi that $X \quad$ Give me that $\mathrm{X}$

\subsection{Sylvie's total inventory of bilingual frames}

$\begin{array}{ll}\text { example } & \text { translation } \\ \text { Der elephant X } & \text { The elephant X } \\ \text { Der X clock } & \text { The X clock } \\ \text { Ein X one } & \text { One X one } \\ \text { Ich like nicht X } & \text { I don't like X } \\ \text { Ich like X } & \text { I like X } \\ \text { Like nicht X } & \text { Don't like X } \\ \text { Und dis one X } & \text { And this one X } \\ \text { Und da is X } & \text { And there is X } \\ \text { Und das is X } & \text { And this is X } \\ X \text { for mir } & \text { X for me } \\ \text { Wo is } X & \text { Where is X } \\ \text { Nein das is } X & \text { No this is X } \\ \text { Das is } X & \text { This is X } \\ \text { Da is } X & \text { There is X }\end{array}$




\subsection{Eetu's total inventory of bilingual frames}

$\begin{array}{ll}\text { example } & \text { translation } \\ \text { Me tosi } X & \text { Me very X } \\ \text { And me tosi } X & \text { And me very } \mathrm{X} \\ X \text { is vessassa } & \mathrm{X} \text { is in the toilet } \\ \text { Tosi } X \text { eyes } & \text { Very X eyes } \\ \text { Kato } \text { me } X & \text { Look, me X }\end{array}$

Bereitgestellt von | Universitaetsbibliothek Leipzig 